\title{
¿ES LA COMUNICACIÓN EN LA EMPRESA UNA COMPETENCIA QUE DEBE DESARROLLARSE?
}

ISSN 2219-6722

ISSNE 2222-2707
Jesús David Argueta Moreno*, Universidad Nacional Autónoma de Honduras (UNAH),
Facultad de Ciencias Económicas, Administrativas y Contables (FCEAC),
Instituto de Investigaciones Económicas y Sociales (IIES),
Ciudad universitaria, edificio C2, primer piso, Tel/fax: (504) 2239-1849
E-mail: jargueta@iies-unah.org/jmartel@iies-unah.org

Justa Rufina Martel, Universidad Nacional Autónoma de Honduras (UNAH), Facultad de Ciencias Económicas, Administrativas y Contables (FCEAC), Instituto de Investigaciones Económicas y Sociales (IIES), Ciudad universitaria, edificio C2, primer piso, Tel/fax: (504) 2239-1849 E-mail: jmartel@iies-unah.org

\section{RESUMEN}

La presente investigación de corte cualitativo, efectúa una reflexión sobre la relevancia del fortalecimiento de las competencias en el ámbito empresarial

Revista Economía y Administración (E\&A) y de forma particular sobre las competencias comunicativas, al desarrollar un reconocimiento el sustento teórico que documenta y describe las bondades originadas por el acertado estímulo/apoyo de las Competencias en la Comunicación. Determinando así la trascendencia de este tipo de competencias, respecto a la adecuada gestión y coordinación de los esfuerzos colectivos e individuales.

Palabras Clave: Competencia, Organización, Procesos, Comunicación, desempeño 


\section{¿ ARE THE COMMUNICATION COMPETENCES A COMPETITION DEVELOP ISSUE? \\ ISSN 2219-6722 \\ ISSNE 2222-2707}

Revista

Economía y Administración (E\&A)

\begin{abstract}
This qualitative research, encourages a reflection over the importance of the skill strengthening on a daily Labored setting, upon the communication capacities, where a rigorous exploration of the theoretical foundations of these theme, intends to describe the benefits obtained from the successful reassurance / support of the Communication Competences. Thereby, determining the enormous implications involved on the proper reinforcement of these type of abilities, regarding the proper management and coordination of individual and collective efforts in the companies.
\end{abstract}

Keywords: Competency, Organization, Process Communication Performance. 


\section{INTRODUCCIÓN}

$\mathrm{E}^{1}$ desarrollo de esta investigación, formalizó un recorrido teórico, el cual abordo los tópicos de comunicación y competencias de forma individual, con el objetivo de encontrar espacios en común o puntos de articulación, donde ambas variables pudiesen converger y así relatar la trascendencia del esfuerzo corporativo contemporáneo en fortalecer las distintas competencias de sus asociados, destacando aquellas pertinentes a las competencias comunicativas.

Lo expresado con anterioridad procura la siguiente interrogante ¿Por qué es tan importante el fortalecer las Competencias Comunicativas en las Organizaciones? La importancia de la competencia comunicativa en toda organización yace en sus bases fundamentales de gestión, pues esta capacidad, habilita el desarrollo humano al posibilitar que los miembros de una comunidad/sociedad reconozcan sus orígenes a través de un sinnúmero de códigos lingüísticos y no lingüísticos y a su vez, acelera la expresión de nuestras ideas, sentimientos, valores culturales y artísticos, al aclarar nuestra complexión como seres humanos, al reafirmar nuestra identidad como tales (Reyes, 2004).

De igual forma, la competencia comunicativa es a su vez un eje transversal en sí misma, al manifestarse como una herramienta integradora de todas las áreas del saber, la cual es fundamental para el fortalecimiento y estabilidad de las sociedades democráticas, al posibilitar la resolución de los problemas, la construcción de acuerdos y la erradicación de prejuicios y la articulación e intercambio de los pensamientos divergentes que agudizan el pensamiento crítico del individuo (Ramos, 2008).

Por otro lado, el ejercicio de esta competencia requiere de la autorregulación de los procesos comunicativos, el cual supone la adaptación de la comunicación a distintas audiencias y situaciones, al evaluar de forma recurrente la efectividad de los modos, medios y estrategias utilizados en los procesos comunicativos (Serrano \& Piñuel Raigada, 1982).

Po lo anterior es pertinente el señalar que en esta investigación se procuró evaluar a la variable comunicación y posteriormente a la variable competencias, para de esta forma determinar si el proceso de comunicación es también, un conjunto de competencias clave para el óptimo desempeño empresarial.

Finalmente, se evaluará el concepto de Competencias Comunicativas desde el ámbito corporativo para esta forma denotar la relevancia e inherencia de este tipo de competencias en el desempeño organizacional de las empresas contemporáneas (ver figura No. 1). 


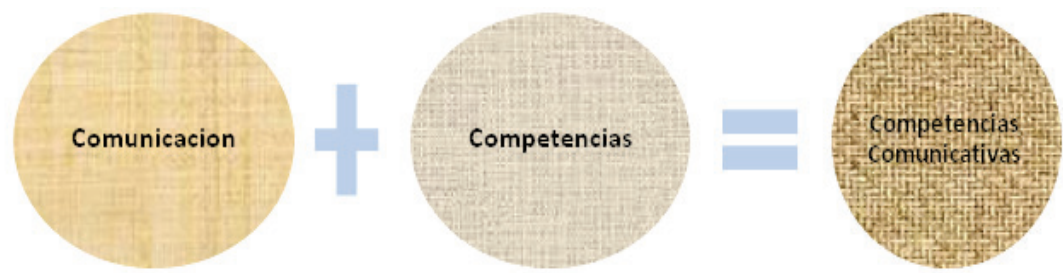

Figura No. 1 Variables en Análisis

Fuente: Interpretación Personal.

Cabe mencionar que a largo de esta pesquisa, se verterán argumento teóricos cimentados/validados, con la finalidad de acompañar a la necesidad de validar la importancia del fortalecimiento las competencias en el ámbito organizacional y para esto, se concatenaran distintas propuestas teóricas, a fin de exponer la necesidad e impacto de esta acción. A continuación se hará referencia a la variable Comunicación.

Revista Economía y Administración $(E \& A)$

\section{LA COMUNICACIÓN}

Pese a que el concepto de comunicación cuenta un vasto número de connotaciones y definiciones, teóricamente validadas y puntuales, este término aún no cuenta con una definición universal y homologada que le permita representar su alcance y gestión con la suficiente aceptación para consolidar los distintos criterios que este concepto contempla, sin embargo entre las más connotadas aproximaciones se destaca a la de:

- Lucas Martín, señala que la comunicación es «el cemento que mantiene unidas las unidades de la organización», pero la comunicación no hay que entenderla únicamente como el soporte que sustenta las distintas actividades de la organización sino que es un recurso, un activo que hay que gestionar (Martin, 2007).

- Martin Satz, propone que la comunicación "es un fenómeno de carácter social que comprende todos los actos mediante los cuales los seres vivos se comunican con sus semejantes para transmitir o intercambiar información" (Satz, 2009).

- Desde el ámbito empresarial, el Dr. Jaime Lacuna Morera, Jefe del Área de Información y Documentación Técnica del Ministerio del Trabajo y asuntos personales de España afirma que La comunicación es un proceso 
por el que los individuos interaccionan entre sí, mediante símbolos que representan información, ideas, actitudes y emociones con el fin de influirse mutuamente.

- En 1986, J Kata y O. Khan, definen que la comunicación es una actividad sustancial a la vida organizacional, definida como: "la red que se teje entre los elementos de una organización y que brinda su característica esencial: la de ser un sistema".

- Finalmente Kurt Lewin en distintas obras, Define el proceso de la comunicación, como un complejo sistema de acciones e interacciones personales y grupales, donde un individuo trasmite un mensaje a otro y éste a su vez responde a otro mensaje, lo que genera un proceso circular y continuo (Lewin, 1935).

Al pretender la integración entre estas definiciones, se asevera que la comunicación es el sistema integrado de actividades que persiguen la óptima interacción y canalización de la información entre individuos en un ambiente/ contexto especifico. Lo que conlleva a la pregunta:

\section{3. ¿ES LA COMUNICACIÓN UN PROCESO?}

Previo a la determinación de la comunicación como proceso, es de vital el describir ¿Qué es un Proceso? así como sus principales características, para luego contrastar estas particularidades con las del término comunicación.

Al definir el concepto de proceso, se recurre a la teoría de sistemas, así como a la guía de la Administración Integral de Proyectos (PMBOK), las cuales basan su misión en procesos de gestión. Donde... por un lado la teoría planteada por Ludwig Bertalanffy en el año 1976 (ver figura No. 2), tipifica que toda realidad puede ser representada de forma sistemática a través de su descomposición en distintos procesos, los cuales a su vez están compuestos por actividades y estas actividades se encuentran integradas por tareas (Bertalanffy, 1976).

De forma complementaria la guía de la Administración Integral de Proyectos (PMBOK) señala lo mismo, con la particularidad que todo proceso se descompone en 3 unidades fundamentales:

- Entradas

- Actividades de procesamiento/Gestión

- Salidas 
Es así que los procesos más allá de encausar insumos / entradas y generar resultados / salidas, presentan una continua modificación del sistema a través del tiempo, al interactuar entre sí (ver figura No. 2).

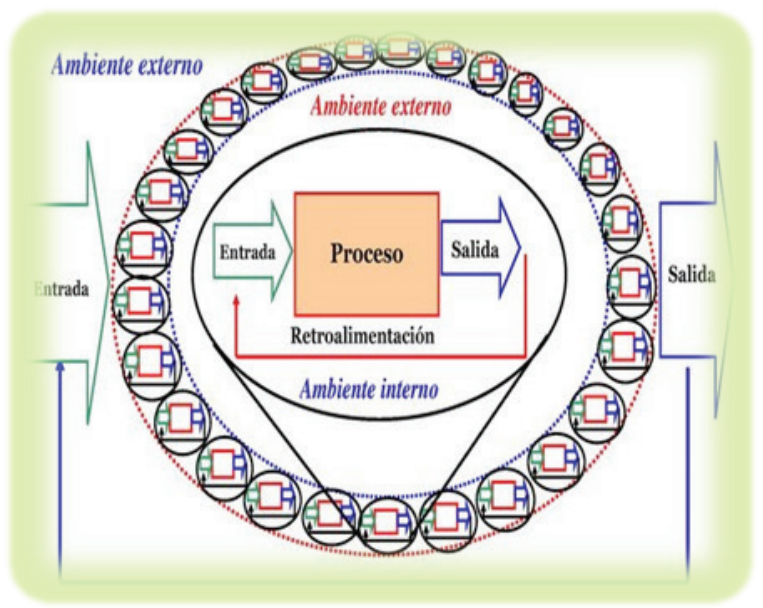

Revista Economía y Administración (E\&A)

Figura No. 2 Representación de la TGS a los procesos L. Bertalanffy

Fuente: L. Bertalanffy, Teoria General de Sistemas, "The Theory of Open Systems in Physics and Biology". En: Science. No3. 1959. Páginas 23-29

Tras revisar la definición ultima, planteada a la luz de la exploración teórica del concepto "Comunicación", y la revisión técnica de un proceso y sus características se infiere que la comunicación, al representar a un sistema interrelacionado de actividades que persiguen la fluida canalización y comprensión de la información, mediante símbolos que representan información, ideas, actitudes y emociones con el fin de influirse mutuamente, es en efecto un proceso (Bachman, 1990).

Por tanto, al identificar de forma concreta a la comunicación como un proceso, compete señalar que este de igual forma representa el intento de unificar dos organismos, por medio de la emisión y recepción de mensajes que tengan un significado para ambos". Esta interacción es esencial para la comunicación humana porque por medio de esta empatía recíproca, el concepto de fuente y receptor se hacen una para formar parte integral del proceso de comunicación, es decir son dos elementos que se unifican para lograr la fidelidad en la comunicación (Arnold, 1989). 
Sin embargo, todos los días los seres vivos nos comunicamos de diferentes maneras, pero sólo los seres humanos podemos hacerlo racionalmente; llevando a cabo infinidad de actividades, tales como: conversar, reír, llorar, leer, ver televisión entre otras; por ello se dice que la comunicación humana es un proceso:

- Dinámico: porque está en continuo movimiento.

- Inevitable: porque se requiere para la transmisión de significados.

- Irreversible: porque una vez realizada, no puede regresar, borrarse o ignorarse.

- Bidireccional: porque existe una respuesta en ambas direcciones.

- Verbal y no verbal: porque implica la utilización de ambos lenguajes.

De cualquier forma, los mensajes se transmiten siempre de la misma manera, basándose en los mismos elementos del proceso los cuales se describen a continuación en la figura No. 3:

- El emisor: Elemento que genera la información y dirige todo su proceso.

- El canal: por donde discurre la información.

- El código usado para la transmisión: palabras o expresiones corporales comprendidas inicialmente de la misma manera por todos los usuarios.

Revista

Economía y Administración $(E \& A)$

- El receptor: Elemento que recibe la información e intenta comprender su significado.

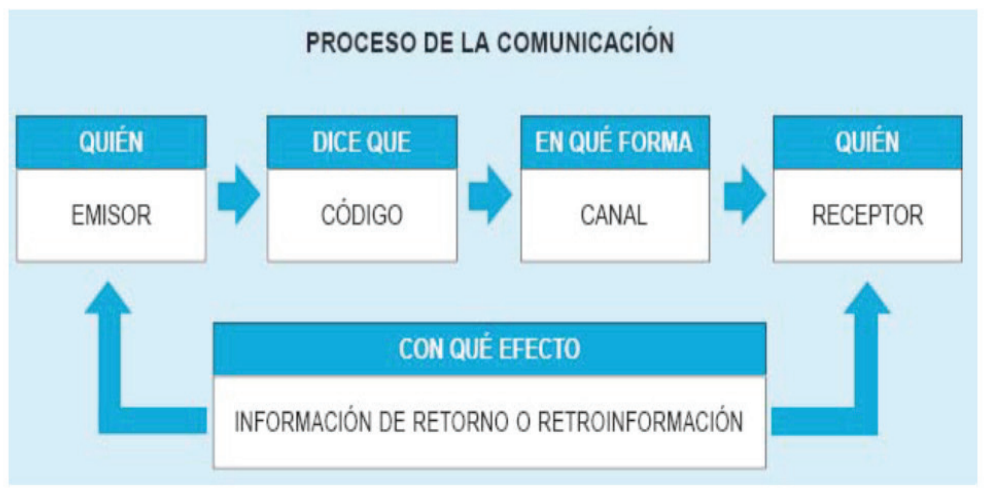

Figura No. 3 Proceso General de la Comunicación

Fuente: La comunicación en las organizaciones, Ministerio del Trabajo y Asuntos Sociales de España, Jaime Llacuna Morera 


\section{BARRERAS EN EL PROCESO COMUNICATIVO}

\section{LOS OBSTACULOS AL PROCESO DE COMUNICACION}

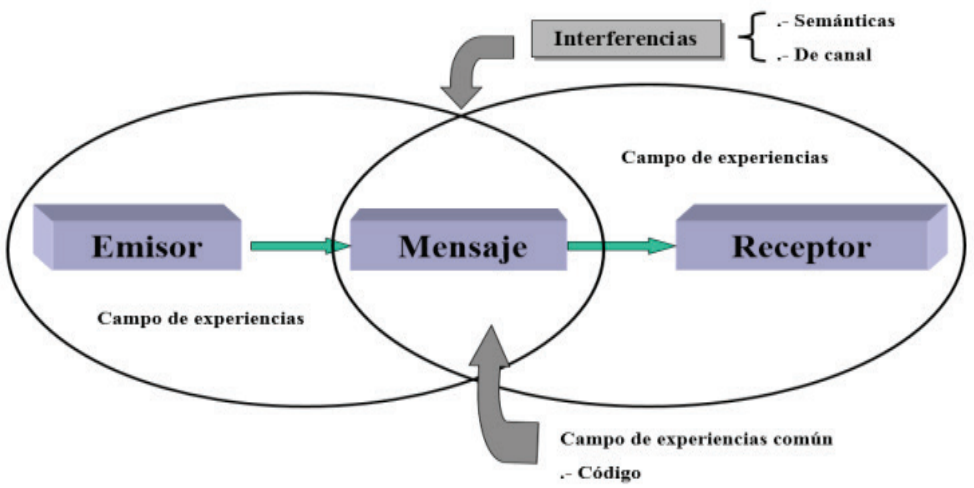

Figura No. 4 Barreras/Obstáculos en el Proceso Comunicativo

Fuente: PhD J. Rodríguez Guarnizo. Didáctica de la química, España, Toledo, U.C.L.M., 1992

Revista

Economía y Administración (E\&A)

\section{ORIGENES DE LA COMUNICACION}

La comunicación a evolucionado de forma iterada con el conocimiento a lo largo de la historia, por lo tanto al procurar dar un adecuado seguimiento a la misma, recurriendo así a la línea de la Teoría del Big Bang, propuesta por Charles Darwin, la cual propone que el ser humano ha evolucionado a nivel social e intelectualmente a través de la comunicación, de igual forma aun y cuando no se cuenta con la suficiente evidencia científica para documentar la presencia del homo sapiens en la tierra más allá del periodo propuesto por Darwin (Reyes, 2004). Distintas investigaciones efectuadas en torno a la evolución de los lenguajes que usaba el homo sapiens, muestran que en efecto no evidencias, para dibujar con propiedad una línea del tiempo en la evolución del proceso comunicativo del ser humano.

Ante esta incertidumbre distintas propuestas evolutivas sean vertido, para proyectar de forma holística la evolución de la mano de la comunicación con la historia humana, entre las cuales figuran:

1. LA TEORÍA DIVINA: Se manifiesta en el Génesis y considera el lenguaje como un don que le fue dado al hombre en el mismo momento de su creación. 
2. LA TEORÍA DE LAS EXCLAMACIONES: Se fundamenta en que el hombre desde muy temprana edad, emite sonidos para expresar sus sentimientos, estados anímicos y emociones.

3. LA TEORÍA ONOMATOPÉYICA: Establece que el origen del lenguaje debió estar en una necesaria imitación de los sonidos que percibían.

4. Finalmente, tenemos la TEORÍA MECANICISTA: Esta se basa en la natural tendencia del hombre a mover sus manos y los músculos faciales en su deseo de comunicarse (la gesticulación).

No obstante y pese a los esfuerzos de un sinnúmero de sociólogos, humanistas y teólogos, de las Teorías presentadas con anterioridad, en ninguna de ellas existe evidencia más antiguas y puntual respecto a la comunicación humana, como lo reflejan las pinturas rupestres del periodo paleolítico superior (unos 30 mil años a.C.) y del magdaleniense (unos 15 mil años a.C.). Donde es válido inferir sobre la complexión de un sistema de numeración y el inicio del lenguaje de contenido estético que va a encontrar su más alta expresión en Egipto posteriormente (Diaz, 1998).

Si bien, distintos autores manifiestan que la comunicación es un proceso sistémico de interacción efectiva, el origen de su asociación con la sistematización de actividades en la transmisión de un mensaje, parte de diferentes modelos. El primero de ellos, y posiblemente el más conocido es el de Aristóteles (334 - 332 a.C.), quien definió científicamente la comunicación, por primera vez, como la "búsqueda de todos los medios posibles de persuasión" (Diaz, 1998).

Después de la muerte de Aristóteles, la comunicación fue olvidada como tema de interés científico. No obstante esta fue retomada de forma indirecta a partir del siglo XVII al manifestarse grandes aportes en la teoría del conocimiento y de forma particular en la década de 1930, en los Estados Unidos de Norte América, cuando un grupo de científicos se interesaron por los estudios de la comunicación, con el fin de potenciar así la industria y optimización del esfuerzo colectivo, motivo por el cual se conoce a sus integrantes como los "padres de la comunicación". Ellos son: Paul Lazarszfeld, Kurt Lewin, Harold Lasswell y Carl Hovland. Lasswell, concretamente, quienes introducen dos elementos esenciales de la caracterización de una comunicación eficiente y eficaz.

El canal en el que se transmiten los mensajes es multivariado y los efectos que éstos producen pueden ser significantes (FINOCCHARO, 1983). 
Revista Economía y Administración (E\&A)

En las décadas siguientes, los estudios sobre la persuasión, conducidos por el grupo de Hovland en la Universidad de Yale (Estados Unidos), como consecuencia de los resultados de la propaganda nazi de la Segunda Guerra Mundial, principalmente llevan a Raymond Nixon (docente en aquel entonces de la Universidad de Yale) a introducir nuevos elementos en el proceso de la comunicación: Las intenciones del comunicador y las condiciones en que se recibe el mensaje (Brumfit, 1980).

Finalizada la destrucción NAZI, dos ingenieros americanos: Claude Shannon y Warren Weaver, diseñaron uno de los modelos contemporáneos de la comunicación electrónica más usados, el cual represento un sistema binario de códigos abiertos, captando y simulando a través de su gestión, un aprovechamiento distinto de las herramientas comunicativas (Brumfit, 1980).

En la década de 1950, Wilbur Shramm adapta el modelo anterior al sistema de comunicación humana, sustituyendo trasmisor y receptor por comunicador y preceptor. De esta forma se establece que la fuente y el comunicador son una persona, que el preceptor y el destino son otra, y que la señal es el lenguaje. Y así nos ubicamos en el campo de la comunicación humana (Marin, 1997).

A posteriori, Wilbur Shramm también introduce el concepto de la codificación de un mensaje, mencionando que al existir una determinada colocación de este en una clave cifrada, hecha por el comunicador; existe la posibilidad de que tanto la fuente como el comunicador sean la misma persona, y que el preceptor y el destino sean la otra persona en la comunicación humana. Pero establece como condición esencial para la percepción del mensaje la experiencia común de comunicador y preceptor con la clave y el significado del mensaje. Si los campos de experiencia del preceptor no son los mismos que los del comunicador, no se comprende el significado del mensaje. Dicha codificación y utilización de claves (lenguaje, por ejemplo) no comunes, genera las "interferencias semánticas" (Rodriguez, 1992).

Finalmente, David K. Balo, en los años 60, formalizó una modificación en el modelo, identificando al codificador y al descifrador independientemente. El codificador que traduce a una clave los propósitos de la fuente y el descifrador que traduce la clave en términos que puedan ser comprendidos por el preceptor. Este concepto es particularmente útil en la información periodística, en cuyo proceso se pueden diferenciar a las personas que cumplen con distintas funciones (Brumfit, 1980). 


\section{TEORÍA DEL PROCESO COMUNICATIVO}

La comunicación está profundamente arraigada en el comportamiento humano y evolución de las sociedades. Por tanto, es difícil pensar en situaciones sociales o de comportamiento en los que la comunicación esté ausente.

Dada la enorme trascendencia de la comunicación sobre el desarrollo humano, surge la iniciativa de La Teoría de la Comunicación, la cual intenta documentar y optimizar el proceso comunicativo, representando una reflexión científica relativamente nueva, la cual estudia la capacidad que poseen algunos seres vivos de relacionarse con otros al verse en la necesidad de intercambiar información. Donde la responsabilidad de la creación de esta teoría, recae sobre el filósofo austriaco-británico Karl Popper el cual describe a la teoría de la comunicación como "la red que tiramos para atrapar al mundo para racionalizarlo, explicarlo y dominarlo" (Popper, 1945).

Denotando que esta propuesta encasilla su análisis en el marco de la interacción de las siguientes variables:

- Fuente: Es el lugar de donde emana la información, los datos, el contenido que se enviará, en conclusión: de donde nace el mensaje primario (Popper, 1945).

- Emisor o codificador: Es el punto (persona, organización...) que elige y selecciona los signos adecuados para transmitir su mensaje; es decir, los codifica para poder llevarlo de manera entendible al receptor. En el emisor se inicia el proceso comunicativo (Popper, 1945).

- Receptor o decodificador: Es el punto (persona, organización...) al que se destina el mensaje, realiza un proceso inverso al del emisor ya que en él está el descifrar e interpretar lo que el emisor quiere dar a conocer. Existen dos tipos de receptor, el pasivo que es el que sólo recibe el mensaje, y el receptor activo o perceptor ya que es la persona que no sólo recibe el mensaje sino que lo percibe y lo almacena. El mensaje es recibido tal como el emisor quiso decir, en este tipo de receptor se realiza el feed-back o retroalimentación (Bachman, 1990).

- Código: Es el conjunto de reglas propias de cada sistema de signos y símbolos que el emisor utilizará para trasmitir su mensaje, para combinarlos de manera arbitraria porque tiene que estar de una manera adecuada para que el receptor pueda captarlo. Un ejemplo claro es el 
código que utilizan los marinos para poder comunicarse; la gramática de algún idioma; los algoritmos en la informática, todo lo que nos rodea son códigos (Popper, 1945).

- Mensaje: Es el contenido de la información (contenido enviado): el conjunto de ideas, sentimientos, acontecimientos expresados por el emisor y que desea trasmitir al receptor para que sean captados de la manera que desea el emisor. El mensaje es la información (Bachman, 1990).

- Canal: Es el medio a través del cual se transmite la información comunicación, estableciendo una conexión entre el emisor y el receptor. Mejor conocido como el soporte material o espacial por el que circula el mensaje. Ejemplos: el aire, en el caso de la voz; el hilo telefónico, en el caso de una conversación telefónica (Satz, 2009).

- Referente: Realidad que es percibida gracias al mensaje. Comprende todo aquello que es descrito por el mensaje (Popper, 1945).

Revista Economía y Administración (E\&A)

- Situación: Es el tiempo y el lugar en que se realiza el acto comunicativo (Bachman, 1990).

- Interferencia o barrera: Cualquier perturbación que sufre la señal en el proceso comunicativo, se puede dar en cualquiera de sus elementos. Son las distorsiones del sonido en la conversación, o la distorsión de la imagen de la televisión, la alteración de la escritura en un viaje, la afonía del hablante, la sordera del oyente, la ortografía defectuosa, la distracción del receptor, el alumno que no atiende aunque esté en silencio. También suele llamarse ruido (Bachman, 1990).

- Retroalimentación o realimentación (mensaje de retorno): Es la condición necesaria para la interactividad del proceso comunicativo, siempre y cuando se reciba una respuesta (actitud, conducta...) sea deseada o no. Logrando la interacción entre el emisor y el receptor. Puede ser positiva (cuando fomenta la comunicación) o negativa (cuando se busca cambiar el tema o terminar la comunicación). Si no hay realimentación, entonces solo hay información más no comunicación (Bachman, 1990).

Señalando que en el ámbito empresarial, la teoría de la comunicación, se centra en la canalización de la información en acorde los roles y funciones de cada asociado/empleado (Popper, 1945). 


\section{FUNCIONES DE LA COMUNICACION}

En el marco de la Teoría de Comunicación, descrita por Karl Popper en 1945, se define que el proceso comunicativo cuenta con 3 funciones esenciales, las cuales permiten y facilitan la libre interacción entre los procesos involucrados en la transmisión efectiva de la información:

- Informativa: Tiene que ver con la transmisión y recepción de la información. A través de ella se proporciona al individuo todo el caudal de la experiencia social e histórica, así como proporciona la formación de hábitos, habilidades y convicciones. En esta función el emisor influye en el estado mental interno del receptor aportando nueva información.

- Afectivo - valorativa: El emisor debe otorgarle a su mensaje la carga afectiva que el mismo demande, no todos los mensajes requieren de la misma emotividad, por ello es de suma importancia para la estabilidad emocional de los sujetos y su realización personal. Gracias a esta función, los individuos pueden establecerse una imagen de sí mismo y de los demás.

- Reguladora: Tiene que ver con la regulación de la conducta de las personas con respecto a sus semejantes. De la capacidad autor reguladora y del individuo depende el éxito o fracaso del acto comunicativo Ejemplo: una crítica permite conocer la valoración que los demás tienen de nosotros mismos, pero es necesario asimilarse, proceder en dependencia de ella y cambiar la actitud en lo sucedido.

\subsection{TIPOS DE COMUNICACION}

Con la finalidad de complementar los distintos elementos de la teoría de las comunicaciones propuesta por el filósofo austriaco Karl Popper, el sociólogo Roger Malicot, en la década de los 60's señala que "la comunicación se puede dimensionar en 3 niveles": el primero o unidimensional (consigo mismo); el segundo, el bidimensional (con los otros); y el tercero, el tridimensional (yo con los otros, el contexto y el medio)" (Marin, 1997).

A continuación indicaremos cada uno de ellos:

I. Comunicación Intrapersonal/Directa o Indirecta/Unidimensional.

II. Comunicación Interpersonal/Bidimensional.

III. Comunicación Masiva/Colectiva/Tridimensional. 
Denotando, que la comunicación se clasifica en directa o indirecta, interpersonal o colectiva.

- Es directa cuando se efectúa sin intermediario de un emisor a un receptor, un dialogo, un conferencista en el auditorio, etc.

- Es indirecta cuando se dan contactos inmediatos entre emisor y receptor y se interpone un intermediario; un documento, un escrito, un casete, etc.

- En la comunicación humana distinguimos varias modalidades en función de la cantidad de personas que intervienen en el acto comunicacional. Así hablaremos de:

- Comunicación intrapersonal: cuando se trata de una comunicación del hombre con sí mismo.

- Comunicación interpersonal: Cuando nos referimos a una comunicación dentro de un grupo.

- Comunicación intergrupal: cuando se establece entre dos o más grupos.

Revista Economía y Administración (E\&A) Existen diferentes razones por las que podemos clasificar los diversos tipos de comunicación.

De igual forma, más allá de las 3 categorías previamente tipificadas, se manifiesta un conglomerado de sub categorías, las cuales emanan de las propuestas principales de, Malicot, a continuación se exponen las sub categorías de las dimensiones del proceso de comunicación:

- Por razón de los canales que sigue la comunicación y su contenido se puede dividir en:

Formal: Se origina en la estructura formal de la organización y fluye a través de los canales organizacionales. Lleva un contenido querido y ordenado por la empresa.

Informal: Surge de los grupos informales de la organización y no sigue los canales formales aunque se puede referir a la Organización, este tipo de organización es de gran importancia, ya que por su característica puede llegar a influir más que la comunicación formal.

- Por razón del receptor puede ser:

Individual: Cuando va dirigida a una persona en concreto.

Genérica: Cuando va dirigida a un grupo sin precisar nombres de personas. 
- Por razón de la obligatoriedad que se espera en la respuesta:

Imperativa: Exige una respuesta precisa.

Exhortativa: Espera una acción sin imponerla obligatoriamente.

Informativa: Simplemente comunica algo, sin señalar nada que se espere, al menos en un plazo inmediato.

- Por razón de su forma de ser:

O Oral

Escrita

Gráfica

- Por su sentido:

Vertical: Cuando fluye de un nivel administrativo superior a uno inferior: "ordenes o instrucciones" o viceversa "quejas, reportes, sugerencias".

Horizontal: Se da en niveles jerárquicos semejantes: "memoranda, circulares, juntas, etc."

\subsection{LA COMUNICACIÓN MODERNA}

La era digital desde la década de 40's, ha permeado las barreras del conocimiento a tal grado, que la utilización de las redes informáticas y los dispositivos auxiliares, se emplean con suma rapidez desde casi cualquier localidad en el mundo, entrelazando a sus usuarios en dinámicos "ecosistemas de red", facilitándoles el acceso a una multitud de bases de datos (Moraba, 2003).

Este desarrollo de en las distintas técnicas en el área de las telecomunicaciones (especialmente la telefonía, la radio, la televisión, y el uso de ordenadores) hacen posible que los sentidos del hombre extiendan su alcance alrededor del mundo. Donde cada uno de los sistemas de esta industria, resulta cada vez más adecuado para transferencia de un determinado tipo de información. Tal es el caso de la extensión en la transmisión de las imágenes animadas a la televisión. La teleinformática traslada datos entre un ordenador emisor y una terminal. Los sistemas de transmisión constan de dispositivos e instalaciones que cumplen distintas funciones, (ampliadores de la potencia, o correctores de distorsiones, decodificadores, entre otros) (Favor revisar la figura No. 5 a continuación). 


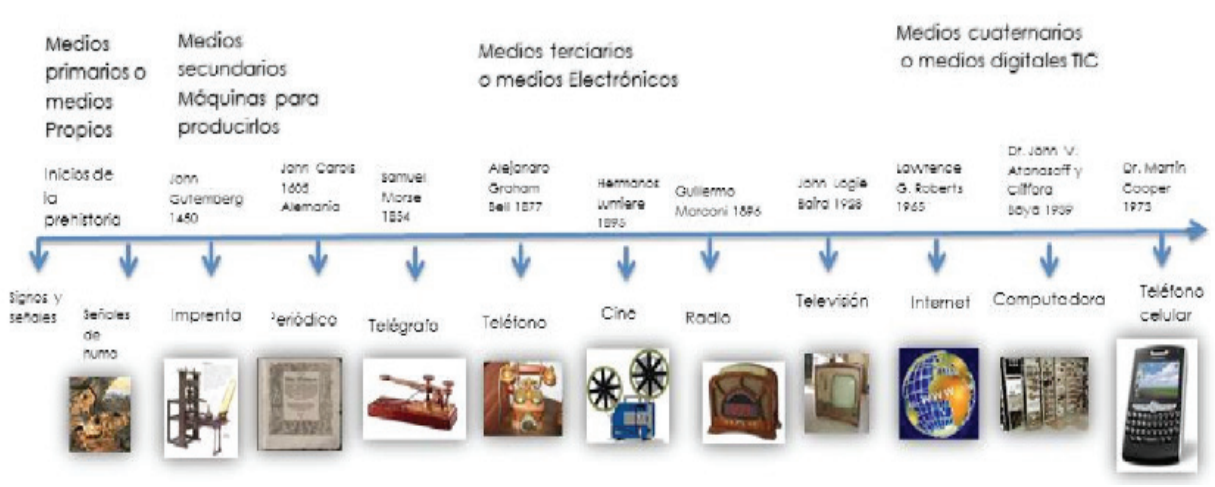

Figura No. 5 Línea de Tiempos Evolución de los Medio s de Comunicación

Fuente: Harry Pross y Mandred Faller, estudio sobre las comunicaciones en la industria, 1972

Revista

Economía y Administración (E\&A)

En la actualidad, la necesidad de los usuarios por comunicarse ha empujado a los sistemas de comunicación satelital y otros medios de comunicación, a utilizar distintas herramientas de corte tecnológico, entre las cuales se destacan e orden cronológico: la telegrafía, telefotografía, telefax, telefonía, el uso de ordenadores o computadores entre otros. Donde...varias de las herramientas tecnológicas previamente citadas pueden compartir con muchos dispositivos y medios, el procesamiento del o los mensajes sobre una amplia gama de actividades de procesado de información (Martin, 2007).

Cabe destacar que del uso de los ordenadores mencionados con anterioridad, los sistemas de redes como Internet permiten intercambiar información entre computadoras, al perseguir la optimización de numerosos servicios que aprovechan esta gestión (Drucker, 1988). En la Era contemporánea el servicio de Internet más reciente e importante es el protocolo de transferencia de hipertexto (http), el cual es el protocolo de transferencia de información que forma la base de la colección de información distribuida denominada World Wide Web o simplemente Internet permite también intercambiar mensajes de correo electrónico (e-mail); acceso a grupos de noticias y foros de debate (news), y conversaciones en tiempo real (chat, IRC), entre otros servicios (Eisenhardt, 1989).

Finalmente "Debido al carácter descentralizado e inabarcable de la Red, la misma Internet censurada ha servido como plataforma de lucha y protesta contra los controles y prohibiciones de impuestos. La misma volatilidad de la Red permite que los sistemas de control sean difícilmente asumibles por los estados. Su uso como vía de información alternativa junto al desarrollo de programas 
que burlan los filtros establecidos preservando el anonimato o el trabajo de los diferentes grupos defensores de los ciber-derechos, son algunos ejemplos de esa lucha contra la censura en Internet. Sin embargo, son bien pocos los organismos oficiales que promueven acciones en este contexto" (Moraba, 2003).

Sin embargo, ya no sólo por las características de la propia red, sino por las de un mundo cada vez más globalizado y cada vez más complicado de frenar en lo que al intercambio de ideas atañe (Eisenhardt, 1989).

\subsection{LA COMUNICACIÓN EN LAS ORGANIZACIONES}

La burocratización de los roles, canales de comunicación y los tipos de relaciones entre los individuos pertenecientes a una organización se remonta a los cambios religiosos ocurridos después de la era del Renacimiento; cuyo principal precursor, Max Weber, define los procesos de intercambio necesarios para asignar y delegar funciones, establecer compromisos, y obtener una canalización de la información ordenada y pertinente (congruente al nivel jerárquico de la empresa en el cual se medite) (Weber, 1903).

La teoría burocrática, tipifica que toda institución debe priorizar dentro de su estructura organizacional un sistema de comunicaciones e información que dinamice los procesos a nivel interno de forma tal que se promueva la participación, integración y convivencia en el marco de la cultura organizacional. En el marco de este escenario, se alimenta el concepto de la comunicación organizacional, desde una perspectiva medida y delimitada, la cual pertenece a una cultura de normas que procuran la difusión de una comunicación formal en el ambiente laboral (Echavarría \& Winckelmann, 1921).

Es así que el término "comunicación” es además un instrumento de cambio, una herramienta de apalancamiento para la difusión, aceptación e interiorización de los nuevos valores y pautas de gestión que acompañan el desarrollo organizacional (Bachman, 1990). Por otro lado, los trabajadores a su vez necesitan estar informados para sentirse parte activa de la organización y que esta participación reciba el adecuado reconocimiento, de tal forma que la comunicación incremente la posibilidad de participación, potencie la formulación de iniciativas y estimule de forma significante a la creatividad de cada asociado/empleado (Maslow, 1954). 
Por lo anterior, se denota que este conglomerado de insumos al mensaje transmitido por los distintos canales de información, a nivel de todo empresa, contribuirá tanto a una mejora de la calidad de vida laboral, como a la calidad del producto ofrecido en la organización misma, lo que de forma concreta sustenta el hecho que en la búsqueda de la calidad total, la comunicación aparece como elemento imprescindible de partida (Echavarría \& Winckelmann, 1921).

$\mathrm{Al}$ afirmar que la gestión de la calidad en las organizaciones se ve alterada por el adecuado gestión del proceso comunicativo en toda empresa, es imprescindible que se describan los procesos que confirman las mejores prácticas para la sobresaliente aplicación de la misma, en el ámbito empresarial (favor revisar la figura No.6 a continuación).

Revista

Economía y

Administración

$(\mathrm{E} \& A)$

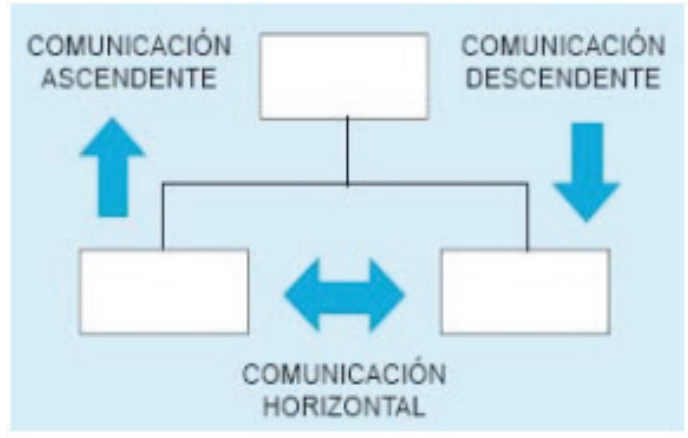

Figura No. 6 La Canalización eficiente de la Información en toda Organización

Fuente: Gabriel Olamendi, Observatorio de Calidad de la Atención en Salud, Ministerio de la Protección Social Colombia, 1995

Si bien la variable comunicación se dimensiona en 3 segmentos:

- Comunicación Intrapersonal

- Comunicación Interpersonal

- Comunicación Masiva

Cada una dimensiones antes mencionadas se manifiesta a lo largo de la vértebra jerárquica de toda organización a través de 3 variantes comunicativas, presentadas a continuación:

I. Comunicación descendente (de la dirección o gerencia hacia el personal): los gerentes y supervisores deben asegurarse que los empleados que les reportan cuenten con la información necesaria para hacer su trabajo de 
forma efectiva. Los mensajes que circulan de arriba abajo se refieren casi siempre a pedidos de información de rutina, también pueden tratarse de ordenes instrucciones o decisiones especificas relativas a acciones a encarar, medidas de organización o medidas personales. La comunicación descendente se caracteriza por poseer un contenido demasiado específico, transmite mensajes predominantemente relacionados con la ejecución y valoración de la tarea, órdenes y especificaciones de trabajo relacionadas con las funciones a realizar, los objetivos a alcanzar, las líneas de acción que conviene respetar, el nivel de cumplimiento de la tarea. (Olamendi, 2008).

II. Comunicación ascendente (del personal hacia la dirección, dirección de la empresa): Los gerentes deben asegurarse que los empleados cuenten con los mecanismos y se vean obligados a mantenerlos informados acerca de los asuntos organizacionales y de negocios. Los mensajes que circulan de abajo a arriba se refieren a las informaciones de rutina necesarias para el trabajo en los diferentes niveles de la empresa. Este tipo de comunicación es de vital importancia en las organizaciones basadas en la información. Muchas de las deficiencias o puntos débiles de este tipo de comunicación podrían evitarse recurriendo al feed-back retroalimentación continua. La comunicación ascendente se convierte en una herramienta que proporciona una retroalimentación importante sobre la efectividad de las comunicaciones descendentes y sobre los problemas de la organización (Olamendi, 2008).

III. Comunicación horizontal (Entre personal de igual jerarquía): Este tipo de comunicación fluye entre los miembros de la organización que se encuentran en el mismo nivel de jerarquía. La comunicación entre compañeros tiende a basarse en el entendimiento mutuo y debido a que unas comunicaciones continuadas forman la solidaridad del grupo, los grupos de trabajo dan una respuesta colectiva a los problemas. La comunicación horizontal tiene diversas funciones importantes: permite compartir información, coordinar y resolver problemas entre las unidades, ayuda a resolver conflictos, permite la relación entre iguales, proporciona apoyo social y emocional en las personas y todos estos factores contribuyen a la moral y la eficacia (Olamendi, 2008). 


\subsection{LA COMUNICACIÓN INFORMAL EN LAS ORGANIZACIONES}

La comunicación informal surge de la interacción social entre los miembros y el desarrollo del afecto o amistad entre las personas, la cual está basada en la espontaneidad, a omitir el protocolo jerárquico de las organizaciones, esta tiene la propiedad de beneficiar o perjudicar a las empresas, según como se aplique (Bachman, 1990).

En apartados anteriores, se menciona que la comunicación es una de los elementos clave para el estímulo de la calidad, sin embargo la mala aplicación de esta puede llevar a la corporación a resultados de desempeño positivo o negativo. En el caso de su efecto positivo, esta forma de canalizar la información puede fortalecer la cohesión del grupo y así dar retroinformación sobre diferentes aspectos del trabajo realizado. Este tipo de comunicación aporta incuestionables beneficios a las personas implicadas en ellas y son útiles a la organización (Jimenez, 1986).

De forma negativa, la comunicación informal puede adoptar una postura errada de rumor o chisme en el ámbito laboral, el cual es un distorsionador de la productividad y no ayuda a la coordinación y acoplo de las organizaciones.

Revista Economía y Administración (E\&A) Allport y Postman lo definen como un enunciado ligado a los acontecimientos cotidianos, destinado a ser creído, transmitido de una persona a la otra, sin que existan datos concretos que permitan establecer su exactitud. Las disfunciones se producen cuando la cohesión se desarrolla en torno a las normas contrarias a las pautas establecidas o cuando estas comunicaciones se traducen en rumorología y dan lugar a un conocimiento generalizado y erróneo sobre temas que afectan a la organización o sobre incidencias personales de sus miembros. Estos rumores se hacen especialmente peligrosos a causa de: los procesos de distorsión a que están expuestos, a la extrema rapidez con que circulan y el gran tamaño de la audiencia y su capacidad de convencimiento y credibilidad (Jimenez, 1986).

\subsection{LA DIFERENCIA ENTRE LA COMUNICACIÓN E INFORMACION}

Este apartado procuro a través del contraste cualitativo entre las variables Información y Comunicación la identificación de las principales diferencias entre las mismas, con el objetivo de encontrar los espacios en los cuales estas variables se complementan y a su vez se distinguen. Para efectos de la agilización de este análisis se recurrió a la Teoría de Sistemas, propuesta por L. Bertalanffy en unidades previas a este documento. 
Al retomar a la teoría de sistemas, se resalta el hecho que la comunicación es un proceso y como tal propicia las relaciones entre los integrantes de toda organización, a través de la adquisición de insumos los cuales recibe, procesa/ gestiona y emite, en este caso información, modelos de conducta, formas de pensar y necesidades de los integrantes (Bertalanffy, 1976).

De esta manera podemos señalar que la información complementa a la comunicación en el sentido que esta representa un insumo (input) para todo proceso expresado a nivel de la teoría de sistemas y este al ser un insumo, complementa la comunicación (el cual es un proceso) ya que lo que se comunica es información procesada en los mensajes o salidas (outputs), por lo que se infiere que es la canal de comunicación y el motivo por el cual se transmite el mensaje, lo que finalmente da sentido la información consignada (Bertalanffy, 1976).

Por lo anterior y de forma general, se percibe que la diferencia fundamental entre estos dos términos reside en la respuesta del interlocutor (feed-back), dado que mientras la información no precisa feed-back par se adecuada gestión, la comunicación si requiere de una adecuada retroalimentación para determinar su adecuada canalización y así seguir estableciéndose (Bachman, 1990).

Una vez explorado el sustento teórico pertinente a la comunicación como tal, compete escudriñar los insumos de la temática de las competencias para de esta forma verificar si la comunicación puede adoptar una postura flexible e ir más allá de su concepción cómo un proceso (la cual ya fue identificada) y pueda esta también interpretarse como una competencia, en este caso una competencia comunicativa.

\subsection{LA COMPETENCIA}

Si bien, a lo largo de la historia, un sinnúmero de sociólogos, humanistas, industriales, entre otros, han abordado el concepto de "competencias", no obstante... dada la vastedad y alcance de la variable, ninguno de ellas(os) ha logrado consolidar una definición universal, capaz de encapsular el término como tal (Campos E. B., 1998). No obstante, en esta investigación se presentan distintas ópticas del concepto, las cuales se articularan de forma recurrente, con el tema de la comunicación en las empresas.

Revista

Economía y Administración $(E \& A)$ 
Por lo expresado con anterioridad, cabe mencionar que en este trabajo se efectuará una aproximación del término competencia, con una orientación al concepto de competencia comunicativa, para luego articular su gestión con las bondades que trae el fortalecimiento de esta a nivel de las empresas.

Citando a continuación a aquellas definiciones más connotadas a nivel del concepto de competencias las siguientes propuestas:

- Schroeder en 1989, sugiere que una competencia es un conjunto relativamente estable de comportamientos, los cuales producen una actuación superior en los grupos de trabajo en ambientes organizacionales más complejos.

- El conjunto de patrones de comportamiento que una persona necesita para desempeñar un puesto de trabajo, de tal manera que lleve a cabo las funciones y tareas correspondientes con competencia (Woodruffe, 1993).

- Una dimensión de conductas abiertas y manifiestas que le permiten a una persona rendir efectivamente (Woodruffe, 1993).

- Características subyacentes de las personas que indican formas de comportarse o pensar, generalizables de una situación o otra, y que se mantienen durante un tiempo razonablemente largo (Spencer y Spencer, 1993).

- Bunke en 1994, asevera que "las competencias profesionales son aquellas sobre las que se dispone de los conocimientos, destrezas y actitudes necesarias para ejercer una profesión, puede revisar los problemas profesionales de forma autónoma y flexible y está capacitado para colaborar en su entorno profesional y en la organización del trabajo".

- Levy en 1996 propone que "las competencias representan un repertorios de comportamientos que algunas personas dominan mejor que otras, lo que las hace eficaces en una situación determinada".

- Según Kobinger (1996), "una competencia es un conjunto de comportamientos socio afectivos y habilidades cognoscitivas, psicológicas, sensoriales y motoras que permiten llevar a cabo adecuadamente un papel, una función, una actividad o una tarea". 
- Stepehnson y York en el año 1998, tipifican que "las competencias representan la Integración de conocimientos, habilidades, cualidades personales y comprensión utilizadas adecuadamente y efectivamente tanto en contextos familiares como en circunstancias nuevas y cambiantes".

Finalmente y tras evaluar algunas interpretaciones del concepto de Competencias, se percibe que las competencias, podrían describirse como aquellos insumos capturados y estimulados por factores contingencia les y situacionales en la vida personal y/o personal de todo individuo, entre estos el conocimiento, experiencias y aptitudes.

Cabe destacar que de la literatura especializada sobre competencias, destacan y son repitentes los siguientes aspectos: las competencias son sistemas de conocimientos, sistemas de habilidades y hábitos, actitudes, expectativas, su relación con la actividad, su orientación a la solución de problemas y toma de decisiones.

Por lo tanto, tras evaluar las definiciones anteriores de competencias, se asevera que estas constituyen la posibilidad real que tiene el ser humano de integrar y movilizar sistemas de conocimientos, habilidades, hábitos, actitudes y valores para la solución exitosa de aquellas actividades vinculadas a la satisfacción de sus necesidades cognitivas (Chomsky, 1970).

Revista

Economía y Administración (E\&A)

\section{ETIMOLOGÍA DEL TÉRMINO COMPETENCIA}

Para abordar el origen del término competencia, es necesario remontarnos a su raíz etimológica, que según Corominas, 1987, proviene del término latín "Competere", que en español cobra sentido en dos verbos "competer" y “competir” (Tobón, 2004).

Dicho lo anterior, es válido inferir que el origen del término competencia, procura la evaluación continua de la competitividad integral, pertinente al desempeño entre 2 o más unidades similares (Hernández, 1998).

\subsection{ORIGEN DEL TERMINO COMPETENCIA}

En el año 2004, Sergio Tobón tipifica en su obra denominada "Formación Basada en Competencias", el origen de las competencias, el cual emana de la 
filosofía griega, debido a la naturaleza y el método del trabajo intelectual de los pensadores de la época.

Posterior a ello, Tobón menciona describe escenarios que dieron aportes significantes al término competencia, figurando entre ellos:

a) La Competencia lingüística, desarrollada por Noam Chomsky, la cual da cuenta de la manera cómo los seres humanos se apropian del lenguaje y lo emplean para comunicarse (Chomsky, 1970).

b) La competencia comunicativa. Desarrollada por Hymes en 1984, esto representó el salto a un concepto más amplio, con el que se pretendía dar cuenta de la capacidad de las personas para determinar cuándo, cómo y de qué forma hablar (Hymes, 1974).

c) El aporte de juegos del lenguaje, donde el significado es el producto del uso del lenguaje dentro de un contexto o forma de vida (Jimenez, 1986).

d) En el ámbito laboral. Martens, citado por Tobón en distintas obras y de forma particular en el año 2004, menciona que el enfoque de las competencias surgió a raíz del requerimiento de las empresas de promover el aprendizaje organizacional, la competencia y la movilidad laboral (Tobón, 2004).

En Países como Inglaterra, Alemania y Estados Unidos, siempre preocupados por tener organizaciones altamente productivas, incursionaron en el campo de la formación de trabajadores y directivos en el modelo de competencias. Destacando que este planteamiento consolida la gestión del talento humano, a partir de la década de los 90's, el cual se basa en competencias y se desarrollan técnicas específicas para llevar a cabo procesos de selección, capacitación, remuneración, evaluación y ascenso, basados en este enfoque.

En la actualidad las grandes empresas acuden generalmente a la psicología, la cual refiere a un papel destacado en la gestión de fortalecimiento y aseguramiento de las competencias organizacionales (Gardner, 1987). En la actualidad los aportes de la psicología cognitiva al enfoque de las competencias se reflejan claramente en tres líneas de investigación:

A. la teoría de la modificabilidad cognitiva, el cual tienen como base el procesamiento de la información mediante operaciones cognitivas, con el fin de realizar actividades en pro de la resolución de problemas.

B. la teoría de las inteligencias múltiples, dentro de la que se contemplan 
siete tipos de inteligencia, además de la lógico matemática y; la enseñanza para la comprensión.

C. La pedagogía laboral y organizacional. También ha tenido aportes en el proceso de consolidación de las competencias. McClellan en el año 1973 planteó que las pruebas tradicionales basadas en la medición de conocimientos y aptitudes, así como las notas escolares, no predecían el éxito en situaciones laborales.

Lo anterior describe la articulación de 3 teorías para explicar el impacto de los elementos de orden causal en los distintos modelos de dirección por competencias a nivel empresarial.

El PhD. Bueno Campos, busco relacionar el CI con el nivel competitivo de una empresa a través de las competencias básicas explicitas dentro de la organización, así como por aquellas especificas del sector, las cuales constituyen un valor critico estratégico en la competencia empresarial el cual amerita una cuantificación. No obstante, para el Dr. Campos, la "competencia esencial" se compone de tres elementos o componentes básicos distintivos: uno de origen tecnológico: esté corresponde al saber y experiencia acumulados por la empresa, otro de origen organizativo: procesos de acción de la empresa y, otro de carácter personal: actitudes, aptitudes y habilidades de los miembros de la organización. De la

Revista Economía y Administración (E\&A) combinación de esas competencias básicas distintivas se obtiene la competencia esencial (Campos, Experiencias de Medición del Capital Intelectual en España, 1999).

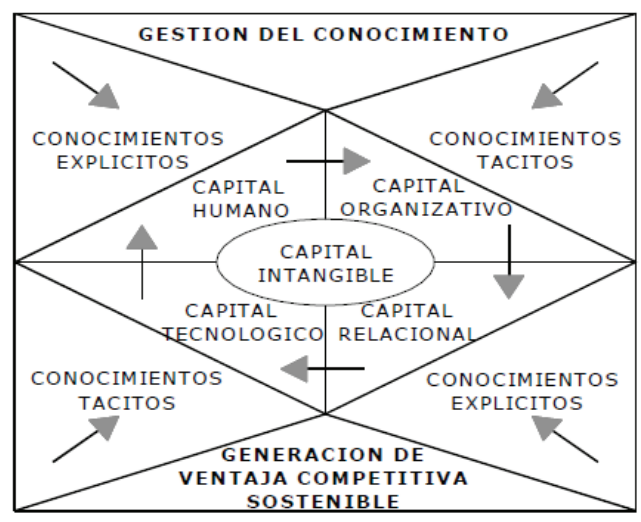

Figura No.7 El capital intangible como generador de ventaja competitiva

Fuente: Eduardo Bueno Campos, Gestión por Competencias, 1998 
El objeto de la Dirección Estratégica por Competencias persigue en primera instancia, la obtención de las distintas pericias, habilidades y conocimientos a través del componente denominado "Competencias Esenciales (CE)", para luego complementar el análisis con elementos de corte técnico, más puntuales como son las Competencias Básicas Distintivas (CBD), las cuales se encargan de analizar la creación y sostenimiento de la ventaja competitiva en el conocimiento tácito (Campos, Organizacion de Empresas, Estructuras, Procesos y Modelos, 2007), ver Figura No. 7 la cual describe la relación entre las dimensiones del capital intelectual y los tipos de conocimiento.

Revista

Economía y Administración (E\&A)

El ser humano ha competido de forma voluntaria e involuntaria en el tiempo, para de esta forma procura hacer valer aquellas habilidades, pericias y conocimientos que le distinguen entre las masas. Dicho lo anterior, se resalta que el concepto de competencia en la comunicación fue utilizado en primera instancia por el lingüista Noam Chomsky, como una medida de desarrollo, para la correcta aplicación de las mejores prácticas en la interiorización de las competencias lingüísticas, lo que implico el descubrir las unidades, estructuras y reglas formales que articulan la lengua del entorno (Chomsky, 1970).

Lo anterior, señala que N. Chomsky en su afán por homologar las competencias lingüísticas, crea la teoría de la sintaxis en el año 1965, la cual establece una distinción entre competencias y actuación. Donde... la competencia, recién se indica, representa el conocimiento que el hablante-oyente tiene en mente socializar, y la actuación hace referencia al uso real de la lengua en situaciones o escenarios particulares.

En un principio, Chomsky aceptó que todos los aspectos relacionados con el uso de las competencias lingüísticas se incluían en la actuación, reconociendo más adelante que algunos aspectos del uso lingüístico diario son sistemáticos y están gobernados por reglas. Por lo que a principios de la década de los 80's, se reconoció, que además de la competencia gramatical, también existe la competencia pragmática. Definiendo a esta competencia pragmática está como el conocimiento de las condiciones y modos de uso apropiado de la lengua conforme a varios objetivos. Este concepto de competencia en la gramática generativa propuesto por Chomsky, era... según algunos de autores en la época, una interpretación de tipo reduccionista, porque en él no se consideraban varios elementos pertinentes, como la escrita y la comprensión del mismo. De forma 
iterada, los sociólogos Campbell y Wales apoyan el planteamiento de Chomsky, al aseverar que el saber de una lengua implica la habilidad de producir o comprender enunciados que son apropiados al contexto en el que tienen lugar (Chomsky, 1970).

Pero sin duda alguna, la reacción de mayor impacto, en términos de la competencia gramatical se dio en la década de los 70's por Dell Hymes, quien consideraba que la competencia gramatical es insuficiente para explicar el uso del lenguaje porque no contempla el hecho de que los enunciados deben ser también apropiados y aceptables en el contexto en el que se utilizan. El contexto de comunicación puede imponer restricciones sobre las formar lingüísticas elegidas en una situación de comunicación determinada. Definiendo así, una posible solución / alternativa al concepto de competencia propuesto competencia de Chomsky originalmente (Chomsky, 1970).

Finalmente, Hymes propuso el concepto de competencia comunicativa que incluye las reglas de uso a las que hace referencia. Anexando a dicho concepto no solo el conocimiento de las reglas gramaticales, sino también la competencia textual o sociolingüística (que no es más que el uso de la lengua en el contexto social (Hymes, 1974).

Revista Economía y Administración (E\&A)

\subsection{TIPOS DE COMPETENCIAS}

Para efectos de este apartado es vital el recurrir a componentes previos en esta investigación en pro su mejor abordaje y comprensión. En esta ocasión, se rescata que en la actualidad no se cuente con una representación universal del concepto competencia, dado que aún no existe una definición concreta, suficientemente capaz de consolidar el termino Competencia como tal y por lo tanto al intentar dimensionarle, este proceso podría ser todavía más complejo (Campos E. B., 1998).

Por lo anterior, se infiere que el pretender dimensionar la variable competencias, en una misma categorización es tan complejo como el hecho de consolidar los criterios para definirle, sin embargo, distintos autores afirman que el termino Competencias representa características de orden contingencial, los cuales atiende al contexto $\mathrm{y}$ factores ambientales $\mathrm{u}$ organizacionales del entorno donde se efectúa el análisis, por lo que no es de extrañar que existan distintas clasificaciones/dimensiones/ tipos de competencias (Campos E. B., 1998). 
Por lo anterior y tal como lo menciona la Lic. Teonila García Zacapa en sus estudios de Dirección por Competencias, existen diferentes formas de ordenar y clasificar las competencias, en acorde a los campos de la Grado Académico, Sector, Nivel de Rendimiento y Actitudes en análisis, sin embargo las que de forma más común se utilizan, para efectos de diseminar y describir la variable, son las pertenecientes al 4 eslabón de la estructura (Clasificación por Sector), presentados a continuación:

1) Ordenamiento de las Dimensiones de la Variable Competencias según el Rendimiento/ Nivel de Desempeño:

A. Competencias diferenciadoras: aquellas características que posibilitan que una persona se desempeñe en forma superior a otras en las mismas circunstancias de preparación y en condiciones idénticas.

B. Competencias de umbral: permiten un desempeño normal o adecuado en una tarea.

Revista Economía y Administración (E\&A)

2) Ordenamiento de las Dimensiones de la Variable Competencias según el Grado Académico/ de Conocimiento:

A. Competencias laborales: propias de obreros calificados, se forman mediante estudios técnicos de educación para el trabajo y se aplican en labores muy específicas.

B. Competencias profesionales: son exclusivas de personas que han realizado estudios de educación superior y se caracterizan por su alta flexibilidad y amplitud, el abordaje de imprevistos y el afrontamiento de problemas de alto nivel de complejidad.

3) Ordenamiento de las Dimensiones de la Variable Competencias a nivel Actitudinal:

A. Competencias técnicas: conocimientos y destrezas requeridos para abordar tareas profesionales en un amplio entorno laboral.

B. Competencias metodológicas: análisis y resolución de problemas.

C. Competencias participativas: saber colaborar en el trabajo y trabajar con otros. 
D. Competencias personales: participación activa en el trabajo, toma de decisiones y aceptación de responsabilidades.

\section{4) Ordenamiento de las Dimensiones de la Variable Competencias por Sector o Industria:}

A. Competencias básicas: son las fundamentales para vivir en sociedad y desenvolverse en cualquier ámbito laboral.

B. Competencias genéricas: comunes a varias ocupaciones o profesiones.

C. Competencias específicas: propias de una determinada ocupación o profesión. Tienen un alto grado de especialización así como procesos educativos específicos.

\begin{tabular}{|c|c|c|c|c|}
\hline \multirow{2}{*}{$\begin{array}{c}\text { Tipo de } \\
\text { competencia }\end{array}$} & \multirow[b]{2}{*}{ Características } & \multicolumn{3}{|c|}{ Ejemplos } \\
\hline & & Enunciado & Descripción & Elementos \\
\hline \multirow[b]{2}{*}{ Básica } & \multirow{2}{*}{$\begin{array}{l}\text { - Base sobre la cual se forman los } \\
\text { demás tipos de competencias. } \\
\text {-Se forman en la educación básica } \\
\text { y media. } \\
\text {-Posibilitan analizar, comprender y } \\
\text { resolver problemas de la vida } \\
\text { cotidiana. } \\
\text {-Eje central en el procesamiento de } \\
\text { la información de cualquier tipo. }\end{array}$} & $\begin{array}{l}\text { Competencia } \\
\text { comunicativa }\end{array}$ & $\begin{array}{l}\text { Comunicar mensajes } \\
\text { acorde con los } \\
\text { requerimientos de una } \\
\text { determinada situación. }\end{array}$ & $\begin{array}{l}\text {-Interpretar textos atendiendo a } \\
\text { las intenciones comunicativas, a } \\
\text { sus estructuras y relaciones. } \\
\text {-Producir textos con sentido, } \\
\text { coherencia y cohesión. }\end{array}$ \\
\hline & & $\begin{array}{l}\text { Competencia } \\
\text { matemática }\end{array}$ & $\begin{array}{l}\text { Resolver problemas con } \\
\text { base en el lenguaje y } \\
\text { procedimientos de la } \\
\text { matemática. }\end{array}$ & $\begin{array}{l}\text {-Resolver problemas con base en la } \\
\text { formulación matemática requerida } \\
\text { por éstos. } \\
\text {-Interpretar la información que } \\
\text { aparece en lenguaje matemático. }\end{array}$ \\
\hline \multirow{2}{*}{ Genéricas } & \multirow{2}{*}{$\begin{array}{l}\text {-Aumentan las posibilidades de } \\
\text { empleo al permitir cambiar } \\
\text { fácilmente de un trabajo al otro. } \\
\text {-Favorecen la gestión, consecución } \\
\text { y conservación del empleo. } \\
\text { - Permiten la adaptación a } \\
\text { diferentes entornos laborales } \\
\text { - No están ligadas a una ocupación } \\
\text { en particular. } \\
\text {-Se adquieren mediante procesos } \\
\text { sistemáticos de enseñanza. } \\
\text {-Su adquisición y desempeño } \\
\text { puede evaluarse en forma } \\
\text { rigurosa. }\end{array}$} & Emprendimiento & $\begin{array}{l}\text { Iniciar nuevos proyectos } \\
\text { productivos o de } \\
\text { mejoramiento de las } \\
\text { condiciones de trabajo con } \\
\text { base en os requerimientos } \\
\text { organizacionales y las } \\
\text { demandas externas. }\end{array}$ & $\begin{array}{l}\text {-Diseñar nuevos proyectos } \\
\text { acorde con los requerimientos. } \\
\text {-Ejecutar los proyectos con } \\
\text { referencia a las metas propuestas. }\end{array}$ \\
\hline & & Trabajo en equipo & $\begin{array}{l}\text { Planificar el trabajo en } \\
\text { equipo teniendo como } \\
\text { referencia los objetivos } \\
\text { estratégicos de la } \\
\text { organización. }\end{array}$ & $\begin{array}{l}\text {-Implementar equipos de trabajo } \\
\text { acorde con las metas organiza- } \\
\text { cionales. } \\
\text {-Negociar conflictos de manera } \\
\text { pacífica, teniendo como } \\
\text { referencia los requerimientos } \\
\text { situacionales. }\end{array}$ \\
\hline \multirow[t]{2}{*}{ Específicas } & \multirow[t]{2}{*}{$\begin{array}{l}\text {-Tienen un alto grado de } \\
\text { especialización. } \\
\text {-Implican procesos educativos } \\
\text { específicos llevados a cabo en } \\
\text { programas técnicos, de formación } \\
\text { para el trabajo y educación } \\
\text { superior. }\end{array}$} & $\begin{array}{l}\text { Diseño del } \\
\text { proyecto } \\
\text { educativo } \\
\text { institucional }\end{array}$ & $\begin{array}{l}\text { Formular el proyecto } \\
\text { educativo con base en a } \\
\text { filosofía institucional, a } \\
\text { política educativa estatal, } \\
\text { la normatividad vigente y } \\
\text { las necesidades del } \\
\text { entorno }\end{array}$ & $\begin{array}{c}\text {-Definir el componente } \\
\text { teleológico del proyecto } \\
\text { educativo con base al diagnósti- } \\
\text { co. } \\
\text {-Trazar la estrategia institucional } \\
\text { en coherencia con las prioridades } \\
\text { del proyecto educativo. } \\
\text {-Formular indicadores para la } \\
\text { evaluación del proyecto } \\
\text { educativo con base en la filosofía } \\
\text { institucional. }\end{array}$ \\
\hline & & $\begin{array}{l}\text { Liderazgo del } \\
\text { proyecto } \\
\text { educativo } \\
\text { institucional }\end{array}$ & $\begin{array}{l}\text { Liderar el proyecto } \\
\text { educativo con base en los } \\
\text { indicadores de gestión } \\
\text { establecidos, las } \\
\text { competencias asignadas y } \\
\text { la normatividad vigente. }\end{array}$ & $\begin{array}{l}\text {-Dirigir los procesos educativos } \\
\text { con base en indicadores de } \\
\text { gestión. } \\
\text {-Establecer alianzas con diferentes } \\
\text { estamentos de acuerdo con la } \\
\text { estrategia institucional. }\end{array}$ \\
\hline
\end{tabular}

Tabla No. 1 Eslabón No. 4 Caracterización y ejemplos de las competencias por Sector/Industria

Fuente: Tobón, S. (2006). Formación basada en competencias. Pensamiento complejo, diseño curricular y didáctica. Bogotá, Colombia: ECOE. 


\subsection{LA COMPETENCIA COMUNICATIVA}

Partiendo de la compleja competencia chomskyana en la que la teoría lingüística se divide en dos partes la competencia y actuación lingüística, surge el término propuesto por Dell Hymes en 1967 "competencia comunicativa" con el fin de profundizar en los conceptos propuestos por Chomsky en 1965.

"La competencia comunicativa es el término más general para la capacidad comunicativa de una persona, capacidad que abarca tanto el conocimiento de la lengua como la habilidad para utilizarla. La adquisición de tal competencia está mediada por la experiencia social, las necesidades y motivaciones, y la acción, que es a la vez una fuente renovada de motivaciones, necesidades y experiencias." (Hymes, 1974).

"La competencia comunicativa comprende las aptitudes y los conocimientos que un individuo debe tener para poder utilizar sistemas lingüísticos y translingüísticos que están a su disposición para comunicarse como miembro de una comunidad sociocultural dada" (Giron \& Vallejo, 1992).

Revista Economía y Administración (E\&A)

Desde muy corta edad el ser humano adquiere la habilidad de distinguir con quien hablar, cuando hacerlo, como tratar con ciertas personas e incluso aprende a evaluar las participaciones de otros individuos. Tomando en cuenta que estas participaciones están relacionadas a los valores del individuo, sus cualidades y a las acciones que originan esta intervención; podemos decir que las competencias comunicativas son un conjunto de normas que se van adquiriendo a lo largo del proceso de socialización y, por lo tanto, están socioculturalmente condicionadas.

Es por ello que la teoría trata con el aspecto "creativo "del lenguaje, es decir, con la destreza del individuo para idearse oraciones nuevas apropiadas a las situaciones. En ese sentido Labov (en 1966) investigó la habilidad de niños negros de la clase baja, en la ciudad de Nueva York, de interpretar oraciones estándar o subestándar; mientras que en su producción utilizan únicamente una fonología subestándar. Mostrando que la conducta es general para todos los códigos de la comunicación, pero se vincula, entre otros, a lo gramatical. Un trabajo como el de Labov en la ciudad de Nueva York, evidencia que la competencia lingüística varía junto con el hablante, señalando la necesidad de un enfoque social. Mostrando que la mayor parte de la dificultad al determinar lo que es aceptable e intuitivamente correcto en una descripción gramatical se deriva de las determinantes sociales y contextuales. Así, esa competencia comunicativa exige no sólo la habilidad para manejar una lengua sino además saber situarse en el contexto comunicativo de 
cada comunidad específica, en sus diversas formaciones sociales y culturales.

Pudiendo percibir el vínculo existente con la parte social cuando en la etnografía del habla, Hymes propone el acrónimo SPEAKING para recoger los componentes del acto comunicativo:

- $\quad$ Situation (situación espacial, temporal y psicosocial).

- Participants (características socioculturales y relaciones mutuas).

- $\quad$ Ends (finalidades).

- $\quad$ Key (clave: grado de formalidad de la interacción).

- Instrumentalities (instrumentos: canal, variedades del habla, cinesia y proxémia).

- $\quad$ Norms (normas de interacción e interpretación).

- Genre (género y secuencias discursivas).

Partiendo de esa descripción, surgieron trabajos como el de Morris Canale en 1983, donde revisa el concepto de competencia comunicativa y distingue cuatro componentes (ver figura No. 8).

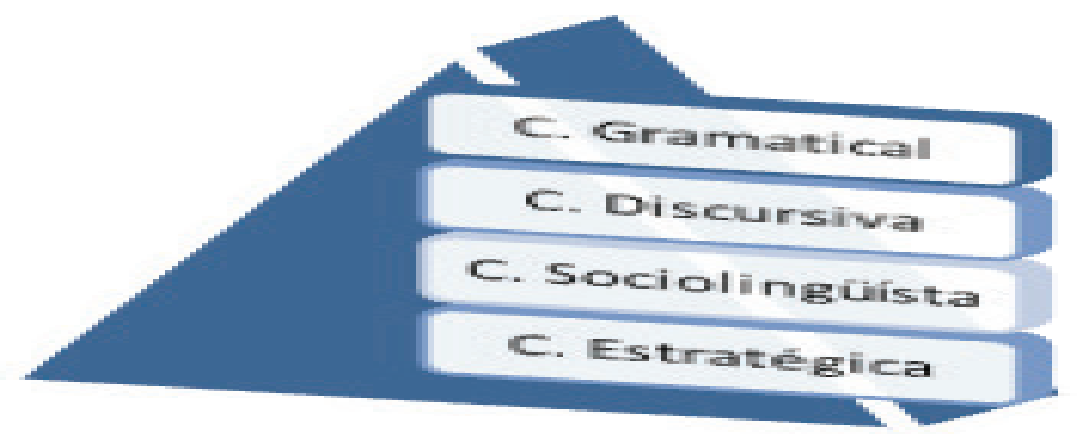

Figura No. 8 Componentes de la Competencia Comunicativa

Fuente: Morris Canale en 1983, Las Compentencias en la Comunicacion 
Años más tarde Lyle Bachman presenta (en 1990) lo que es actualmente uno de los marcos teóricos más completos para comprender las distintas variables que afectan la habilidad de comunicación lingüística (Hymes D. ,1974), revisar figura No. 9 donde se parametrizan las dimensiones de la competencia comunicativa.

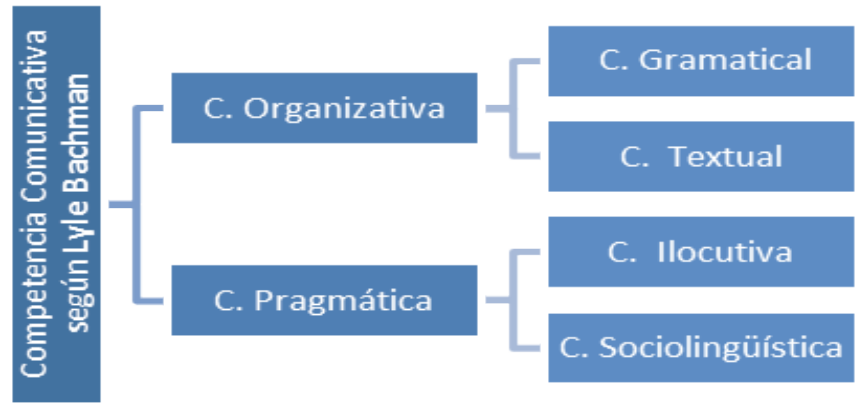

Figura No. 9 Dimensiones de las Competencias Comunicativas Fuentes: Dimensiones de la Competencia Comunicativa, según Lyle Bachman, 1990

Revista Economía y Administración (E\&A)

\section{EL FORTALECIMIENTO DE LAS COMPETENCIAS: COMUNICATIVAS VS. LAS LABORALES}

Este apartado tiene como su principal objetivo el exponer las bondades del fortalecimiento de las competencias en las empresas, al procurar la articulación del concepto "Competencias Comunicativas" con el término "Competencias Laborales", con la finalidad de mostrar que las Competencias Comunicativas, más allá de pertenecer a la clasificación de competencias por sector, también forman parte del bloque de competencias clasificadas según su grado académico (Campos E. B., 1998). 
No obstante, previo a la asociación de las Competencias Comunicativas con las Competencias Laborales, es vital la descripción de las competencias laborales como tal.

Por lo anterior se menciona... que las competencias laborales, representan el "conjunto de destrezas, habilidades, conocimientos y características conductuales que frente a una situación de trabajo, predicen un desempeño superior, distingüendo el rendimiento excepcional del promedio, el cual es observable a través de las conductas de cada empleado en la ejecución diaria de su cargo" (Hernández, 1998).

Brevemente, se tipifica que el concepto de "competencias laborales" ha cobrado mayor relevancia en el mundo corporativo; sin embargo, este concepto surge en Europa alrededor de la década de los 80's como marco de referencia para la administración y desarrollo del personal en las empresas, como una respuesta inmediata a las distintas exigencias manifiestas para contar con personal altamente capacitado que pueda contribuir con la obtención del éxito empresarial, destacando que son precisamente las competencias laborales, las que representan la punta de lanza entre las herramienta de la Administración del Recurso Humano (Popper, 1945).

¿Por qué entrelazar la Competencia Comunicativa con la Laboral?

Revista

Economía y Administración (E\&A)

Al ser la Competencia Laboral, el primer frente de evaluación y análisis de gestión, por parte de la dirección del conocimiento empresarial, es de enorme trascendencia para esta investigación el encaminar la localización de los puntos de articulación entre los mismos. Señalando que son precisamente las competencias laborales las que son sometidas a una "evaluación empresarial" la cual emana de la evaluación del desempeño y/o rendimiento efectuado por el patrono hacia su(s) asociado(s)/empleado(s) en un marco de temporal especifico (Ramos, 2008).

Dicho en otras palabras: Las Competencias Laborares hacen referencia a la cuantificación del impacto en adiestramiento corporativo a la luz de los esfuerzos a favor del fortalecimiento y potenciación los de las competencias, con la premisa de medir la efectividad de los talleres y capacitaciones impartidas a los empleados (Brumfit, 1980).

A partir de la explicación previa, conviene intentar una rápida relación entre la llamada "gerencia del conocimiento" (Dirección del Conocimiento Empresarial) con otras dos expresiones de fuerte vigencia en el ámbito empresarial: El 
Fortalecimiento del Capital Intelectual y La potenciación del Aprendizaje Organizacional. En los cuales... una aproximación esquemática reporta que el patrimonio de un país, en su dimensión más elemental, está integrada por el capital físico vinculado a los bienes tangibles y mensurables, al capital social relativo de las condiciones que aseguren niveles de vida así como actitudes culturales de convivencia; y el capital intelectual corresponde al conjunto de activos intangibles potenciables (competencias) (Jimenez, 1986).

En definitiva, al estar consciente de que la expresión "gerencia del conocimiento" no puede ser destronada sólo resta la responsabilidad de sostener que, en lugar de abordar la cuestión como una confrontación entre una u otra opción, preferimos favorecer una conjugación en donde se acepte que al hablar de gerencia del conocimiento se está pensando en gerencia de las competencias (Hernández, 1998).

\subsection{MECANISMOS PARA EVALUAR Y FORTALECER LAS COMPETENCIAS COMUNICATIVAS EN LAS EMPRESAS}

Revista Economía y Administración (E\&A)

Dentro los mecanismos contemporáneos dedicados a evaluar y potenciar a las competencias, se destacan a los sistemas denominados: "Coaching", Mentoring, Autodesarrollo, entre otros.

A continuación, se presentan algunas herramientas para fortalecer las competencias en el ámbito empresarial:

1. El Mentoring: Se trata de un proceso de mejora, a través de la guía de un mentor o líder flexible, que otorgue apoyo continuo a los colaboradores.. La esencia está en el "learning contract", que marca la pauta del proceso de desarrollo. $\mathrm{Al}$ establecer normas de conducta, donde el mentor y el participante definen como se va a desarrollar su relación, teniendo en cuenta los objetivos de cada uno (Drucker, 1988).

2. Auto-desarrollo: Al contrario del mentoring, el auto-desarrollo es un proceso de mejora individual, sin la guía de un líder. Este método permite acercar a los participantes a los requisitos óptimos de desempeño en su función actual dentro de la organización (Drucker, 1988). 


\section{CONCLUSIONES ABORDADAS TRAS EL RECONOCIMIENTO TEORICO PERTINENTE A LA COMPETENCIA COMUNICATIVA EN LAS EMPRESAS}

Al escudriñar el sustento teórico pertinente al fortalecimiento de las competencias comunicativas en el ámbito empresarial se puede argumentar lo siguiente:

- La comunicación más allá de obedecer a una secuencia sistémica de actividades, es un proceso integral el cual gestiona un mensaje a través de 3 componentes: Entradas (Insumos), Herramientas y Salidas.

- Las Competencias pueden agruparse en 4 bloques generales según la finalidad del análisis de las mismas:

a) Competencias según el Grado Académico.

b) Competencias Según el Sector/Industria.

c) Competencias según el nivel de Rendimiento y Desempeño.

d) Competencias según el grado de aptitudes del individuo.

- El proceso Comunicativo, cuenta con ciertas propiedades / características que le permiten adquirir la categorización de una competencia sectorial.

- Las Competencias Comunicativas pertenecen al Grupo de Competencias denominado "Competencias por Sector/Industria" y de forma específica a las competencias básicas.

- LasCompetenciasComunicativascuentaconunenfoquemayoritariamente social el cual se encuentra muy ligado a las competencias de corte laboral y por tanto le permiten a la dirección de toda empresa u organización, la cuantificación del impacto de las iniciativas de fortalecimiento a estas, en el marco de las competencias básicas.

- Las Competencias Comunicativas en el contexto empresarial exigen a todo individuo no sólo la habilidad para manejar una lengua sino la pericia para situarse en el contexto comunicativo de cada unidad empresarial, en sus diversas formaciones y culturales. 
- La sistematización de los canales y formatos de comunicación en las empresas contemporáneas, agilizan el flujo de la información a lo largo de la misma, con la particularidad de la despersonalización de las relaciones interpersonales entre los asociados.

- Finalmente las Competencias Comunicativas en las empresas, se pueden fortalecer a través de:

- La burocratización de los roles y niveles jerárquicos en las empresas.

- La sistematización de los canales de información y socialización en la empresa.

- La adecuación de códigos, para las funciones y requerimientos a nivel departamental

- Una adecuación de la tecnología a los flujos de la información en la empresa.

- Entre otros. 


\section{REFERENCIAS BIBLIOGRÁFICAS}

Arnold, M.,1989. Teoría de Sistemas, Nuevos Paradigmas: Enfoque de Niklas Luhmann. Revista Paraguaya de Sociología. Año 26. Nº75, Páginas 51-72.

Bachman, L.,1990. Fundamental Considerations in Language Testing. Oxford, Reino Unido: Oxford University Press.

Berruto, G., 1979. La semántica. Ciudad de Mexico Distrito Federal, Mexico: Editorial UNAM.

Bertalanffy, L., 1976. Teoría General de los Sistemas. Mexico: Editorial Fondo de Cultura Económica.

Brumfit, C., 1980. The essentials of a communicative curriculum in language teaching. Applied Linguistics, Pgs 89-112.

Campos, E. B., 1998. Modelo Intellectus: Medición y Gestión del Capital Intelectual. Madrid, España: Editorial UAM.

Campos, E. B., 2007. Organizacion de Empresas, Estructuras, Procesos y Modelos. Madrid, España: Piramide.

Chomsky, N., 1970. Aspectos de la teoría de la sintaxis. Madrid, España: Editorial Aguilar.

Davis, J., \& Newstrom, A., 1988. El comportamiento humano en el trabajo. Ciudad de Mexico, Mexico: McGraw Hill.

Diaz, N., 1998. Lenguaje y Comunicación. Valencia: Universidad Jose Antonio Paez.

Drucker, P., 1988. Administración para el Futuro. Estados Unidos de Norte America: University Press.

Echavarría, J. M., \& Winckelmann, J., 1921. Economía y Sociedad. Munich, Alemania.

Eisenhardt, K., 1989. Building Theories from Case-Study Research. Academy of Management Review, Vol: 14 (4) 532-550.

Finoccharo, M., 1983. The Functional Notional Approach. Oxford: Oxford University Press. 
Revista Economía y Administración (E\&A)

Gardner, H., 1987. Las estructuras de la mente. La teoría de las inteligencias múltiples. . Ciudad de Mexico D.F.: Fondo de Cultura Económica.

Giron, L., \& Vallejo., 1992. Producción e interpretación textual. Medellin, Colombia: Universidad de Antioquia.

Giron, M. S., \& Vallejo, M. A., 1992. Producción e interpretación textual. Antioquia Colombia: Editorial Universidad de Antioquia.

Girón, M., \& Vallejo, M., 1992. Producción e interpretación textual. Medellín: Universidad de Antioquia.

Hernández, C., 1998. Una propuestade evaluación por competencias. Bogotá, Colombia: ICFES.

Hymes, D., 1974. "Hacia etnografías de la comunicación”. En: “Antología de estudios de etnolingüística y sociolingüística". Mexico: UNAM.

Hymes, D., 1974. "Hacia etnografías de la comunicación". En: Antología de estudios de etnolingüística y sociolingüística. Ciudad de Mexico Distrito Federal, Mexico: Editorial Universidad Nacional Autonoma de Mexico (UNAM).

Hymes, D., 1974. Hacia etnografías de la comunicación”. En: “Antología de estudios de etnolingüística y sociolingüística. Mexico: UNAM.

Jimenez, J., 1986. Competencia lingüística y competencia comunicativa. Antioquia, Colombia: Editorial Universidad de Antioquia.

Labov, W., 1996. The Social Stratification of English in New York City. New York, US: Centre of Applied Linguistics.

Lewin, K., 1935. Una teoría dinámica de la personalidad. Iowa, Estados Unidos de Norte America: IOWA University Press.

Marin, A., 1997. La Comunicacion en las Empresas y en las Organizaciones. Barcelona, España: 1era Edición, Editoria 1 Trillas.

Martin, L., 2007. La Globalizacion en los medios de Comunicación. Cordova, Argentina: Valencia : Le Monde diplomatique, edición española.

Maslow, A., 1954. Motivación y personalidad. Brooklyn Nueva York, Estados Unidos de Norte America.

Moraba, A. R., 2003.

Censura en la Red: Restricciones a la libertad de expresión en Internet. 
Segovia, España: Universidad SEK de Segovia.

Olamendi, G., 2008. Guía Pedagógica Estrategias De Comunicación, Motivación y Liderazgo Orientadas al Fortalecimiento Del Proceso De Cultura Organizacional. Colombia: Observatorio de la Calidad de la Atencion al Cliente.

Popper, K., 1945. La Sociedad abierta y sus enemigos. Austria: University Press.

Ramos, J. A., 2008. Las competencias comunicativo-lingüísticas de tipo disciplinar. Perfiles profesionales y recursos para su desarrollo en el nuevo siglo. Actas del XXXVII Simposio Internacional de la Sociedad Española de Lingüística (SEL) (págs. Pgs 64-78). Pamplona, España: Editorial de la Universidad del Pais Vasco.

Reyes, M. R., 2004. El Desarrollo de Competencias Comunicativas: uno de los Principales Retos en la Educación Superior a Distancia. Latin Educa 2004, Primer Congreso Latino Americano de Educacion a distancia (págs. 42-62). Mexico: Facultad de Estudios Superiores Acatlán, UNAM.

Rodriguez, J., 1992. Didacttica de la Quimica. Toledo, España: UCML.

Rojas, V. M., 1998. Los Procesos de la Comunicación y del Lenguaje. Bogota, Colombia: ECOE, Santa Fe de Bogotá.

Satz, M., 2009. Manual de la Comunicación. Madrid, España: Editorial de la Universidad Complutense de Madrid.

Serrano, M. M., \& Piñuel Raigada, J. L., 1982. Teoria de la Communicación I. EPpistemologia y Analisis de la Referencia. 2 (págs. Pgs 56-77). Madrid, España: Gráficas Valencia, S. A. Paseo de Talleres, 18. Madrid-21.

Tobón, S., 2004. Formación basada en competencias Pensamiento complejo. Bogotá, Colombia: ECOE.

Weber, M., 1903. La ética protestante y el espíritu del capitalismo. Munich, Alemania: Archiv für Sozialwissenschaft.

Este artículo fue seleccionado de trabajos presentados en la Primera Conferencia Internacional sobre Economía, Administración y Tecnología, evento organizado por el Consorcio Economía, Administración y Tecnología (CEAT). El documento original ha seguido el proceso de revisión estándar de la Revista Economía y Administración (E\&A). El proceso fue dirigido por Marvin Aguilar (CEAT-2013) y supervisado por el PhD. Jorge Flores Silva, y MSc. Manuel Flores Fonseca (Editores de E\&A). 